DOI: http://dx.doi.org/10.23925/2176-2767.2020v69p53-89

Recebido em: 30/06/2020 Aprovado em: 12/08/2020

\title{
ARTIGO
}

\section{"LA CUESTIÓN DE LÍMITES": INTELECTUAIS, DIPLOMATAS E A DISPUTA PELAS FRONTEIRAS ENTRE ARGENTINA E CHILE (SÉCULOS XIX A XXI)}

\author{
"LA CUESTIÓN DE LÍMITES": INTELLECTUALS, \\ DIPLOMATS AND THE BORDER DISPUTE BETWEEN \\ ARGENTINA AND CHILE (19TH TO 21 ${ }^{\text {ST }}$ CENTURIES)
}

\author{
GABRIEL PASSETTTI ${ }^{1}$
}

\section{RESUMO}

Os Estados argentino e chileno atualmente são divididos pela terceira maior linha fronteiriça do mundo e, desde a segunda metade do século XIX, houve intensos debates intelectuais sobre as áreas a serem controladas por cada país. O artigo relaciona como a intensificação da produção daqueles homens colaborou para levar aquele debate entre as chancelarias para a esfera pública, mobilizando e construindo rivalidades, antagonismos e tensões internacionais que quase levaram à guerra em três oportunidades. Seu objetivo central é debater as conexões entre intelectuais, diplomatas, políticos e militares em perspectiva comparada e conectada, tendo como foco o debate sobre a linha internacional de fronteiras.

PALAVRAS-CHAVE: Fronteiras; Argentina; Chile; Intelectuais.

\begin{abstract}
The Argentine and Chilean States are nowadays divided by the third largest border line in the world and, since the second half of the 19th century, there have been intense intellectual debates about the areas to be controlled by each country. The article associates the intensification of the production of those men and mobilization and construction of international rivalries, antagonisms and tensions that almost led to the war on three occasions. Its main objective is to debate the connections between intellectuals, diplomats, politicians and the military in a comparative and connected perspective, focusing on the debate on the international border line.
\end{abstract}

\footnotetext{
${ }^{1}$ Doutor em História Social (USP), professor de História das Relações Internacionais (UFF), vinculado ao Programa de Pós-Graduação em Estudos Estratégicos (PPGESTUFF). E-mail: gabrielpassetti@id.uff.br, ORCID: 0000-0001-8311-5396. Este texto apresenta resultados preliminares de pesquisa desenvolvida com bolsa Produtividade em Pesquisa CNPq-2 e bolsa Faperj JCNE.
} 
KEYWORDS: Borders; Argentina; Chile; Intellectuals.

Os Estados argentino e chileno atualmente são divididos por aquela que é a terceira mais longa linha fronteiriça do mundo, com mais de cinco mil quilômetros de extensão. Construção abstrata sobre a terra, essa divisão entre os Estados é fruto de intensas negociações e do esforço intelectual de elaboração de diferenciações entre populações um tanto semelhantes e de homogeneizações entre aqueles alocados dentro de um espaço dito nacional. Este artigo analisa esse caso com o objetivo de apresentar possíveis diálogos entre a História das Relações Internacionais e a História Intelectual, com ampliações nos temas, forças e atores a serem considerados para a análise.

Há muito se discute como as fronteiras são construções históricas, políticas e sociais, mas aqui propomos a ampliação desse debate, indicando como os intelectuais contribuíram, nesse caso específico, para a construção de antagonismos, rivalidades e argumentos que embasaram as iniciativas das chancelarias. Apresentamos aqui as conexões entre a intensificação da produção e dos debates intelectuais e a construção de crises internacionais entre os dois países, em especial quanto às disputas por territórios fronteiriços.

Ao abordar a chamada cuestión de limites entre os Estados argentino e chileno como uma construção e como influenciável à atuação de intelectuais, expressamos a participação dos atores não-estatais em um tema tão caro às análises clássicas da História das Relações Internacionais. Ao incluirmos os intelectuais e seus debates, também procuramos demonstrar como a História Intelectual pode contemplar 
temas e fontes pouco explorados pela área, geralmente associados a uma antiga História Diplomática.

Para a análise, foram pesquisadas, nas Bibliotecas Nacionais da Argentina e do Chile, aquelas obras que exploravam a cuestión de limites. Demos especial atenção para aquelas que apresentavam debates com outras contemporâneas e as que foram incorporadas pelas chancelarias ou pelas imprensas nacionais para embasar suas reivindicações, indicando a circulação e esforço daqueles intelectuais para estabelecer uma agenda política, participar dos debates e ganhar protagonismo.

Entendemos os intelectuais como integrantes das elites e com acesso aos meios de divulgação de ideias e aos grupos de formuladores e tomadores de decisão. Procuramos inserir a produção daqueles homens nos debates contemporâneos sobre nação, território e soberania. Ao analisar a produção intelectual nesta perspectiva, entendemos que

as "ideias", o "pensamento" estão sempre enraizados em um contexto histórico específico, e isso implica que estejam sempre "marcados", no que tange à sua possível gama de significados, pelas crenças, atitudes, esperanças, forças materiais e simbólicas de comunicação e, ainda, pelas imaginações possíveis da época em cujo interior se situam (MYERS, 2016, p. 26).

Os livros, panfletos e discursos elaborados e intensamente divulgados por aqueles homens foram parte de um debate intelectual transandino, envolvendo argumentações, contra argumentações e muitas acusações estando repletos dessas marcas sociais e temporais. Também pensamos essa história em uma história de conexões intelectuais, procurando demonstrar que, mesmo um tema tradicional da História das Relações Internacionais, pode e deve ser revisitado a partir da ampliação de fontes e questões, como as oriundas da História Intelectual. Para a 
análise, recorremos à história comparada, entendendo que é preciso escolher

dois ou mais fenômenos que parecessem, à primeira vista, apresentar certas analogias [...]; em seguida, descrever as curvas de sua evolução, constatar as semelhanças e as diferenças e, na medida do possível, explicá-las à luz da aproximação entre uns e outros [...], estudar paralelamente sociedades vizinhas e contemporâneas, sociedades sincrônicas, próximas umas das outras no espaço (PRADO, 2005, p. $17-18)$.

Dividido em quatro partes, o artigo primeiro apresenta breve histórico sobre a construção dessa imensa linha fronteiriça. Depois são explorados os debates intelectuais da segunda metade do século XIX, suas conexões com as atuações das chancelarias dos dois Estados, as tensões militares e seus principais produtos: as assinaturas do tratado de limites de 1881 e dos chamados Pactos de Maio de 1902. Após estes, o tema deixou de ser foco até meados do século XX, quando novas tensões internacionais, potencializadas por novos estudos sobre a fronteira quase levaram a novo conflito entre os governos ditatoriais no final da década de 1970. Por fim, são analisadas as obras do período democrático e como estas procuraram construir novos discursos de confiança e integração, criticando os textos nacionalistas anteriores.

\section{A terceira maior linha fronteiriça do planeta e um imenso território em disputa}

Na segunda metade do século XIX, com o avanço dos processos de consolidação dos Estados argentino e chileno, as elites, seus diplomatas e militares passaram a debater quais os efetivos limites 
territoriais sobre os quais as soberanias seriam exercidas, já que as linhas oficiais de fronteiras estavam indefinidas.

Havia uma relativa concordância sobre os Andes demarcarem a separação nas áreas sobre controle estatal desde os tempos coloniais, mas pouco ou nenhum consenso sobre até onde iam os territórios mais ao sul, em especial sobre o controle da Patagônia. Isso se dava porque a imensa área delimitada pelo sul das províncias de Buenos Aires, Córdoba, San Luis e Mendoza no lado oriental da cordilheira, e a Araucania do lado ocidental, sempre esteve sob o controle efetivo indígena.

A partir de meados do século XIX, ocorreram com cada vez mais intensidade e violência operações militares para a ocupação daquelas terras. Aquelas elites adaptaram os discursos sobre superioridade racial, potencialidades econômicas e soberania em discursos marcados por um “colonialismo pós-colonial” (HARAMBOUR, 2019).

No entanto, a essas mesmas elites políticas americanas, uma série de temas disputava as prioridades. No caso da Argentina, a ameaça brasileira era muito mais real do que a chilena. Já para esse país, os interesses sobre as áreas de extração de guano e salitre de Peru e Bolívia eram mais sedutoras do que a concorrência com os argentinos pela Patagônia.

$\mathrm{Na}$ primeira metade do século, houve pouca atuação de ambos Estados na região. Ao mesmo tempo em que as províncias platinas se fragmentavam e guerreavam em seu longo processo de unificação, os chilenos inseriram em sua constituição de 1822 e nas seguintes sua 
delimitação territorial no deserto do Atacama ao norte, na cordilheira dos Andes a leste e no Estreito de Magalhães a sul.

Com este objetivo, o Estado chileno executou seu mais importante avanço naquela região na década de 1840, ao instalar o forte Bulnes e depois fundar Punta Arenas no Estreito. Aquelas ações foram estrategicamente importantes, pois praticamente todo o comércio internacional do Chile se dirigia ao Atlântico e o controle daquela passagem era essencial para garantir a segurança dessas operações.

O governo da província de Buenos Aires também realizou sucessivas operações militares ao sul, sobre os pampas, mas ainda em área muito distante do extremo sul do continente. Em 1828, foi fundada a fortaleza "Protectora Argentina" na costa atlântica mais de mil quilômetros ao sul da capital (mas ainda aproximadamente dois mil quilômetros distante do Estreito).

A circulação de criollos $^{2}$ pelo sul do continente ainda era rara e a presença estatal ínfima. Entre as próprias elites políticas portenhas e chilenas, não havia muito interesse nem clareza sobre qual Estado poderia reivindicar títulos históricos sobre aquela região, herdados da administração colonial espanhola.

Como não havia consenso sobre os documentos coloniais, nem tampouco havia presença efetiva de qualquer Estado naquela área e os indígenas mantinham resistências obstinadas às expansões criollas, as chancelarias aprovaram a redação de um artigo vago em tratado assinado em 1855, segundo o qual "Ambas partes contratantes reconocen como limites de

\footnotetext{
${ }^{2}$ Criollos são os descendentes de espanhóis nascidos na América.
} 
sus respectivos territórios los que poseían tales al tiempo de separarse de la dominación española el año 1810" (Artigo XXXIX).

A partir desse tratado, iniciou-se um primeiro movimento de tentativa de expansão sobre aqueles territórios, com o Estado chileno criando a província de Arauco no mesmo ano em que Buenos Aires autorizou a instalação de uma colônia na foz do rio Santa Cruz (1859). Apesar dessas e de outras iniciativas, a presença estatal na região permanecia ínfima.

No entanto, a unificação argentina, a partir de 1862, e a vitória daquele país na Guerra do Paraguai (1870), alteraram as capacidades daquele Estado. Para compreender a virada das preocupações e interesses argentinos para a Patagônia, é preciso destacar uma série de fatores.

A disseminação de imagens e relatos sobre a violência indígena, na imprensa e na literatura, ajudou a fortalecer um ideário já em circulação sobre um embate entre a "civilização" e a "barbárie". Interessados em ocupar as terras dos povos nativos, os colonos criavam situações de violência para acionar as preocupações na capital e angariar apoio, seja na Argentina, seja no Chile, para o envio de tropas regulares para o combate aos cacicados.

Neste processo, denominado de "colonização da barbárie" (PASSETTI, 2010), recorrer a potencialidades econômicas das terras não exploradas, ao branqueamento da população do país e à ameaça do país vizinho sobre aqueles territórios foi central. Na Argentina, após a Guerra do Paraguai, a expansão estatal sobre os pampas e depois sobre a Patagônia foi bastante rápida, sendo marcada por expedições militares de 
aniquilação das resistências indígenas, entre 1878 e 1879, denominadas de "Conquista do Deserto".

Não apenas a chancelaria chilena, como parte dos intelectuais acompanhou de perto essa movimentação. Como não havia definição sobre o controle sobre o Estreito de Magalhães e como havia, da parte de determinados grupos, a reivindicação sobre territórios patagônicos a leste dos Andes, a tensão diplomática cresceu exponencialmente.

Até 1875 as negociações foram controladas por Adolfo Ibañez, chanceler chileno, e Félix Frías, ministro argentino em Santiago e ambos defendiam pretensões bastante amplas para seus Estados sobre o território em disputa. Naquele ano, uma sucessão de eventos alterou a política internacional. Os chanceleres foram alterados em abril (Chile) e agosto (Argentina) e, na sequência, aquele país assinou, em março de 1876, seu tratado de fronteiras com o Paraguai, diminuindo drasticamente a tensão na bacia do Prata. Suposições entre possível aproximação entre Chile e Brasil aterrorizavam a Argentina, enquanto a provável aliança daquele país com Peru e Bolívia eram uma preocupação real para Santiago.

Esta conjuntura regional é importante de ser destacada, já que a partir de 1875 se verifica, com o novo chanceler chileno José Alfonso uma nova política, priorizando os interesses no norte - que levariam à Guerra do Pacífico em 1879. Tentativas de se chegar a acordos, ocorreram em 1874, 1877, 1878 e 1879, mas nenhum deles conseguiu a ratificação dos Congressos de ambos países.

A eclosão da Guerra do Pacífico ao mesmo tempo em que se iniciava a campanha militar final da "Conquista do Deserto" aguçou os 
ânimos belicistas, com uma série de militares argentinos da ativa se alistando para lutar pela aliança anti chilena. Esta mobilização foi respondida com uma ampla e heterogênea aliança política com o objetivo de manter a neutralidade para alcançar bons resultados na negociação pela Patagônia.

Foi ainda durante a Guerra do Pacífico, mas já após a estrondosa vitória da batalha de Arica (junho de 1880) que as negociações avançaram e chegaram a um tratado de fronteiras, em 1881. A linha final, definida no tratado enfim ratificado pelos dois Congressos, foi definida como "os altos picos que dividem águas" nos Andes e linhas retas a partir dali, fazendo com que o Chile controlasse todo o Estreito (mas não o militarizasse), sem acesso daquele país ao Atlântico e ainda com a divisão da ilha da Terra do Fogo e arquipélago adjacente.

Este resultado final levou a intensa controvérsia nas imprensas, entre os intelectuais dos dois países. Em 1893, foi assinado um primeiro protocolo adicional, mas a situação se resolveu somente em 1902, levando a uma escalada de tensões e uma corrida armamentista que levou ambos Estados a construírem marinhas de guerra comparáveis às das grandes potências da época (HEINSFELD, 2019). Em meados do século XX, a polêmica ressurgiu com debate sobre qual Estado controlava algumas ilhas menores ao sul da Terra do Fogo. Nova crise militar alcançou pico em 1978 quando guerra quase foi declarada e a mediação do papa arrefeceu os ânimos (VILLAR, 2016).

A partir desse breve histórico, pretendemos demonstrar como a disputa da linha de fronteiras entre os Estados argentino e chileno não envolveu interesses econômicos mais claros, mas foi essencialmente 
sobre expectativas de soberania e identidades, construídas, alimentadas e potencializadas pelos intelectuais que analisaremos na sequência.

\section{Os intelectuais, a diplomacia e a projeção de territórios e soberanias para o período colonial}

Cada uma das fases das tensões internacionais descrita anteriormente foi antecedida de exaustiva produção intelectual e da participação de seus autores em debates públicos. As esferas tradicionais dos poderes decisórios foram ultrapassadas, demonstrando a criação de agendas públicas e a atuação de agentes não estatais em um debate sobre soberania e nação que mobilizou públicos mais amplos e, como pretendemos demonstrar, influenciou as decisões de diplomatas e militares.

Naquele momento, não havia a distinção entre o político, o diplomata e o intelectual, havendo muitos casos em que uma mesma pessoa circulava por esses diferentes grupos, estes mesmos muito restritos e comunicativos entre si. O foco da análise recai sobre estes que demonstraram interesse, capacidade de mobilizar o debate público e interferir nas políticas do Estado. Até o período da assinatura dos Pactos de Maio de 1902, houve intensa profusão de publicação de livros e panfletos daqueles homens, especialmente interessados em participar e influenciar o debate público.

Eles escreveram sobre o que eram os territórios argentino e chileno, a "justiça" das reivindicações de seu Estado, procurando oferecer provas documentais do período colonial que justificassem tais 
reivindicações, em produtos intelectuais marcados pelo discurso positivista na História e também pelo uso tendencioso das fontes para amparar determinados discursos diplomáticos.

Logo após a instalação do forte Bulnes e da criação da colônia de Punta Arenas no Estreito pelos chilenos, o governador da província de Buenos Aires, Juan Manuel de Rosas, encomendou a Pedro de Angelis, intelectual de origem italiana (SCHEIDT, 2008) a construção da argumentação portenha para o controle da Patagônia. Em Colección de obras impresas y manuscritas que tratan principalmente del Río de la Plata, de 1852, ele dedicou toda uma seção às zonas em litígio pela Confederação Argentina: o Chaco, costas da Patagônia, Estreito de Magalhães e Terra do Fogo, e ilhas Malvinas (DE ANGELIS, 1852). Sua atuação demonstra os vínculos entre os intelectuais, a construção de uma linha de fronteiras e o entendimento da época de que a disputa internacional também foi jurídica e histórica, abrindo espaço aos profissionais especializados no manejo desse ferramental.

Ali teve início a primeira fase do intenso debate intelectual entre argentinos e chilenos, com resposta publicada no ano seguinte por aquele que seria o principal articulador, em Santiago, das posições expansionistas sobre a Patagônia. Miguel Luis Amunátegui, então um jovem liberal, premiado e recém-formado na Universidad de Chile (PACHECO, 2012), publicou Títulos de la República de Chile a la soberanía $i$ dominio de la estremidad austral del continente americano, em 1853, defendendo não apenas o controle do Estreito, mas de toda a Patagônia pelo Chile. Participar do debate parecia, a um jovem sem muitas posses e fora dos 
círculos do poder, uma oportunidade para se colocar na política e defender o que entendia como "os direitos históricos da pátria".

O texto do chileno recebeu imediata e negativa recepção na Argentina, com recebeu resposta publicada, no mesmo ano, pelo veterano jurista Dalmacio Vélez Sarsfield, sob o título de Discusión de los titulos del gobierno de Chile a las tierras del Estrecho de Magallanes (1853) em que este defendia toda a Patagônia, Estreito e Terra do Fogo à Argentina, a partir de documentos coloniais guardados em Buenos Aires. Esta argumentação foi, novamente, contestada por Amunátegui, em 1855, com panfleto de mesmo título que o anterior, encerrando esta primeira fase do debate. A disputa não girava sobre potencialidades econômicas, mas sobre "justiça”, "direito" e "pátria”.

Este intenso debate antecedeu a assinatura do tratado de 1855 ajuda a entender como, diante de tamanha controvérsia e disputa, foi redigido o artigo tão amplo e ambíguo já citado. O interessante é verificar como, em ambos Estados, viu-se a necessidade de tornar público este debate, abrindo espaço para mobilizações públicas e para a ascensão política e intelectual dos autores dessas justificativas.

Com a indefinição sobre as fronteiras e jurisdições e diante de tão extensas áreas em litígio, intelectuais argentinos e chilenos permaneceram mobilizados para o O levantamento, em seus arquivos coloniais e naqueles localizados na Espanha, de documentos históricos que pudessem amparar as pretensões de ocupação daquelas terras.

O debate reacendeu em 1865, quando Manuel Ricardo Trelles, publicou Cuestión de limites entre la República Argentina y el gobierno de la República de Chile no contexto da assinatura de tratado entre a Argentina e 
a Bolívia, com reflexos diretos sobre reivindicações dos dois países e o Chile. Personagem central, mas pouco explorada nos debates sobre o que se convencionou chamar na historiografia de cuestión de limites, Trelles era um dos intelectuais mais destacados entre os portenhos daqueles anos, tendo sido, desde 1858, diretor do Arquivo Nacional (PODGORNY, 2011).

Seu trabalho foi central para o levantamento dos documentos coloniais espanhóis. Mais para a frente, quando a disputa diplomática atingiu níveis elevados, conseguiu a aprovação para o envio de Vicente Quesada, então diretor da Biblioteca Pública à Espanha, em 1873, para a obtenção de cópia de documentos. O tempo todo, buscou-se argumentar historicamente os "direitos", evitando-se a escalada militar.

Dois anos após aquela viagem, Quesada publicou La Patagonia y las tierras australes del continente americano, causando enorme impacto no embasamento diplomático argentino com a "descoberta” de Real Cédula de 1570 com a designação da Patagônia a Buenos Aires sem, no entanto, apresentar cópia da tal. A partir destes casos, é interessante verificar como este debate da cuestión de limites foi intencionalmente transformado em público para que se mobilizasse paixões, discursos e interesses na defesa de cada argumentação e também se verificasse quais angariavam mais apoio, já que dentro de cada país havia diferentes projetos em disputa.

Naquele clima político de pressão diplomática e percebendo a necessidade de difundir e defender suas teses sobre os direitos argentinos sobre aqueles territórios, Félix Frías, ex-ministro argentino em Santiago, político de longeva carreira, publicou Cuestión chileno-argentina: notas 
diplomáticas y otros escritos en defensa de los derechos de la República Argentina (1877). Aquele livro foi o principal mobilizador dos discursos mais exasperados contra um chamado expansionismo chileno e teve uma trajetória distinta: veio de um negociador e político defendendo suas posições.

A aprovação da viagem de Quesada não passou desapercebida no Chile. Os diplomatas Manuel Antonio Matta e Carlos Morla Vicuña, então em Paris, foram acionados para viagem urgente a Madri para semelhante coleta de documentos. Desta expedição, resultaram as primeiras publicações diretamente relacionadas a diplomatas profissionais: La cuestión chileno-argentina (1874) por Motta e La cuestión limites entre Chile y la República Argentina (1879), por Morla Vicuña, indicando a profissionalização e o aumento da tensão do caso, mas também a manutenção do caráter público do debate e a mobilização.

Segunda missão diplomática chilena foi enviada à Espanha, em 1877, após o fracasso da negociação de tratado. Participava da missão o jovem Gaspar Toro Hurtado que publicou, no ano seguinte, La diplomacia cbileno-arjentina: cuestión de límites. Seus argumentos não satisfizeram os discursos nacionalistas mais exaltados de Santiago e seu chefe, Barros Arana, foi retirado da missão em Buenos Aires, onde tentava negociar novo acordo.

Sem sair do Chile, mas contando com muitos dos documentos levantados por seus colegas, Amunátegui não deixou de ficar de fora desta nova fase da disputa diplomática e intelectual, pretendendo reforçar a defesa do controle sobre a Patagônia contra as posturas mais contidas de políticos e empresários locais. Ele aumentou seu ritmo de 
trabalho e publicou, em três tomos, entre 1879 e 1880 a enciclopédica La cuestión de limites entre Chile i la República Arjentina.

Como procuramos demonstrar, há direta correlação entre os picos de negociações diplomáticas e a produção intelectual destes homens que circulavam não apenas por arquivos e bibliotecas, como também pelos Parlamentos, chancelarias e pela imprensa. Cada vez mais os homens envolvidos diretamente nas negociações entraram no debate público.

Esta intensa produção intelectual, que acompanhou e alimentou as disputas políticas e diplomáticas e o tensionamento das rivalidades militares, acabou mobilizando intensos debates nos Parlamentos, com as seguidas não ratificações de tratados por uma ou outra casa legislativa dos países em litígio.

A corrida para a os arquivos americanos e depois europeus naquelas décadas não foi privilégio de argentinos e chilenos, mas sim prática comum de praticamente todos os Estados latino-americanos por conta das negociações das linhas de fronteiras. Nos casos aqui analisados, havia muita ambiguidade na documentação colonial espanhola e esta produção intelectual tendeu, portanto, a destacar aqueles registros - ou apenas trechos deles - em que suas teses eram fortalecidas, sonegando ou até mesmo adulterando outros para tentar enfraquecer o discurso adversário.

À medida em que os embates entre ambos países se tornavam públicos e mobilizavam paixões em torno de supostas soberanias sobre territórios jamais controlados no período colonial, aqueles intelectuais e diplomatas cada vez mais políticos passaram a explorar as incoerências 
da documentação espanhola. Chilenos passaram a reivindicar a Patagônia inteira e partes dos pampas até próximo a Buenos Aires, enquanto argentinos pretendiam afirmar títulos históricos sobre regiões nas costas do Pacífico até a Araucania.

Esse acalorado debate foi explorado com muita atenção por vários historiadores, como Pablo Lacoste (2002), Andrés Cisneros (2000), Carlos Escudé (1988), Alberto Harambour Ross (2019) e Agustina Reyes (2010), entre os mais recentes. Não é nossa intensão aqui aprofundar os usos e abusos dessa documentação histórica por cada um desses autores do século XIX, mas sim indicar como houve intensa vinculação entre a produção e publicação intelectual e os debates internacionais.

Neste sentido, é possível entender como aqueles homens investiram no que Lacoste chamou de "Chile fantástico" e "Argentina fantástica", aquelas ampliações aparentemente absurdas de territórios: mais do que reivindicações que se pretendia ver contempladas em qualquer processo de arbitragem, se pressionava o país vizinho e se apresentavam reivindicações territoriais bastante estendidas para garantir o que se considerava como o mínimo necessário. A grande polêmica era sobre terras não atribuídas a nenhuma das divisões administrativas espanholas: o extremo sul da América, o Estreito de Magalhães e a Terra de Fogo e arquipélago circundante.

Como bem definiu o historiador chileno Alberto Harambour, os Estados pós-coloniais se organizavam para exercer, naquelas áreas, uma nova versão do colonialismo espanhol da qual eram herdeiros. A resolução das disputas de delimitação começou a ser produzida pela via dos fatos, como correlato da dimensão diplomática e historiográfica que ocupou mais pessoas, mais recursos e 
definitivamente mais papel do que sua implementação no terreno (HARAMBOUR, 2019, p. 52).

A ratificação do tratado de 1881 não resolveu as disputas entre os dois Estados. Uma vez que os chilenos estavam preocupados com a ocupação do Peru e da Bolívia e, depois, com a incorporação efetiva dos territórios ao Chile, os argentinos passaram a pressionar pelos trabalhos da comissão científica encarregada de desenhar no terreno a linha de fronteiras. As tensões ressurgiram, por conta das distintas interpretações do tratado, e levaram ao Protocolo Adicional, de 1893, seguido logo de um livro de memórias e defesa da posição chilena por Diego Barros Arana, seu negociador.

Tanto o Protocolo Adicional quanto os Pactos de Maio, de 1902, foram a solução diplomática de contenção a discursos nacionalistas e belicosos em ambos países, mas em especial na Argentina. Figura central foi Estanislao Zeballos, advogado e escritor.

Com suas três breves passagens pela chancelaria marcadas por tentativas de rever os tratados de limites com diferentes países e o exacerbamento de um discurso nacionalista potencializado por suas inserções na imprensa e no Congresso (GREJO, 2017). A corrida armamentista das décadas de 1880 e 1890, as tensões e a cristalização de um discurso, na Argentina, sobre um Chile expansionista, se deveram em muito à atuação intelectual, política e jornalística de Zeballos e à sua leitura sobre as relações entre os dois países, o equilíbrio regional e a importância do uso da força nas relações internacionais.

A assinatura dos "Pactos de Maio", em 1902 pareceu selar uma paz definitiva entre ambos Estados e também marcou o fim de um tipo 
de produção intelectual sobre as fronteiras. Nas décadas anteriores, a efusiva produção esteve diretamente associada às negociações diplomáticas e envolveu, em sua fase mais tensa, a participação ativa de integrantes dos corpos consulares divulgando suas pesquisas em arquivos locais e espanhóis e suas teses através de livros, panfletos e escritos nos jornais, indicando a intensidade dos debates domésticos e internacionais.

Naqueles anos, a construção de imagens e identidades sobre o país vizinho e as tentativas de associar territórios a documentos produzidos pela administração colonial espanhola tiveram como resultado a produção de muitos livros e panfletos pela defesa de supostas soberanias, que estimularam o debate público e levaram à não ratificação de uma série de tratados, a corridas armamentistas, à ocupação de terras indígenas até, por fim, durante a Guerra do Pacífico, a um arranjo binacional com um texto um tanto ambíguo.

Quando descrito por uma História das Relações Internacionais tradicional, este processo foi naturalizado como resultado de negociações diplomáticas e debates políticos, excluindo-se a vertente pública e intelectual, crucial para a definição do resultado final.

\section{Projeções sobre o Chile expansionista e a Argentina oportunista}

Após os acordos de 1902, o assunto saiu das pautas de diplomatas, militares e intelectuais por muito tempo. A única exceção foi a publicação de livro do jurista e político de longa carreira, ex-chanceler e candidato derrotado à presidência Luis Barros Borgoño (1936). Ele publicou pouco antes de assumir a embaixada em Buenos Aires, 
defendendo a atuação de seu tio, Diego Barros Arana, e as políticas conciliatórias por ele manifestadas na crítica década de 1870 . O tema das fronteiras, parecia superado.

No entanto, a situação mudou no final dos anos 1950. Após a Marinha Argentina impedir a instalação de equipamentos navais por sua contraparte chilena, em 1958, no ilhote Snipe no canal Beagle, ao sul da Terra do Fogo, explodiu imensa polêmica sobre o controle daquela e de outras três ilhas um pouco maiores (Nueva, Picton e Lennox) que seria resolvida apenas duas décadas depois.

Não havia recursos naturais de destaque, nem tampouco aqueles territórios eram estratégicos ou imensos, mas a disputa pelas ilhas se tornou central nos discursos nacionalistas de argentinos e chilenos e esteve acompanhada, como demonstraremos, de nova fase de intensa produção intelectual.

Em 1959, Francisco Antonio Encina, um dos mais destacados historiadores chilenos do período (ARANDA, 2009), já àquela época reconhecido pelo trabalho de vinte volumes de sua Historia de Chile foi quem reiniciou o debate. Seu La cuestión de límites entre Chile y la Argentina desde la independencia hasta el tratado de 1881 é, até hoje, um dos livros referência sobre o tema para a história diplomática.

É evidente a influência intelectual da obra de Amunátegui para a elaboração da análise do conservador hisoriador. Nessa nova obra, há a retomada da "tese fundacional", isto é, dos direitos chilenos sobre grande parte da Patagônia a partir dos documentos históricos espanhóis. Para ele, os políticos chilenos estavam contaminados pelo "vírus americanista", pacifista e entreguista e teriam combatido e impedido a 
defesa dos interesses chilenos diante dos argentinos. Para ele, não se tratava de uma disputa econômica, mas moral sobre justiça e direito de soberania do Estado chileno e o caráter de suas elites, pouco engajadas na defesa dos "interesses nacionais".

A principal hipótese sobre a qual se centra Encina é este embate entre um grupo embasado e "certo", caracterizado por Amunátegui e pelo chanceler Ibañez, atacado e derrotado por outro. Estes "pacifistas" não carregavam, para ele, o espírito orgulhoso chileno dos tempos coloniais e pressionaram o presidente Errásuriz a arrefecer a pressão sobre a república vizinha em momento que eram política e militarmente mais fortes do que os portenhos. Para ele, o Chile havia "renunciado voluntariamente" à Patagônia diante de uma Argentina ainda fraca. Em sua análise, a "perda" da Patagônia não era decorrência da justiça, dos títulos, do direito ou das habilidades da chancelaria argentina, mas sim das debilidades chilenas e do oportunismo dos vizinhos em 1881. Ele manteve uma leitura sobre populações e territórios que projetava no passado colonial um Chile pré-existente e demograficamente homogêneo e conservador, como faziam seus ideólogos da segunda metade do século anterior.

Este tipo de interpretação da história e das relações bilaterais, em um momento de recrudescimento das disputas diplomáticas, levou a ainda um maior tensionamento ao se disseminar rapidamente pela intelectualidade, políticos e formadores de opinião pública. Sendo Encina um dos maiores expoentes do pensamento conservador chileno do século XX (CRISTI e RUIZ, 1990), suas interpretações alcançaram ampla divulgação dentro daquele grupo, tornando-se referenciais para o 
principal manual de história das relações internacionais daquele país, o Historia diplomática de Chile (1541-1938), de Mario Barros van Buren (1970).

Entre a publicação do livro de Encina e a de Mario Barros, a tensão cresceu nas relações entre as duas chancelarias. Em 1965, foi acionado o artigo do tratado que informava a arbitragem britânica às controvérsias (SANTOS, 2016). Neste contexto, os argentinos voltaram à produção intelectual sobre o tema: defesa territorial e soberania pareceram ser temas que podiam sair das tecnicidades das chancelarias e mobilizar o debate público.

Foi no mesmo ano de 1965 que o jurista Exequiel Bustillo publicou seu Problemas de nuestra frontera patagónica. Nesta obra, ele fez o resgate da leitura nacionalista do século XIX, em especial aquela de Félix Frías, pautada por descrição sobre um expansionismo chileno diante de uma passividade argentina, com afirmações contundentes como: "Esta penúria geográfica é o fator geopolítico que provoca essa permanente inquietude territorial do Chile, que pouco significaria se não estivesse estimulada pela negligência argentina na administração e manejo de sua própria terra de fronteira" (BUSTILLO, 1965, p. 22).

O livro de Bustillo foi importante por resgatar, na Argentina, a produção intelectual sobre a cuestión de límites, que mobilizava seus pares no outro lado da cordilheira e, especialmente os diplomatas, os militares e os políticos. Como o laudo arbitral britânico não contemplou a disputa sobre as ilhas do canal Beagle, o governo chileno solicitou nova análise, em 1967, mas diante de intensa pressão doméstica, o governo argentino do general Ongania rejeitou tal solução. 
Neste clima de acirramento das tensões entre os nacionalistas de ambos países, é interessante verificar como o tema mobilizou também aqueles que se encontravam no outro campo do espectro político. $\mathrm{Na}$ Argentina, seis intelectuais peronistas, reunidos no Instituto Rosas (NEIBURG, 1997), apesar de perseguidos e de terem perdidos seus direitos políticos, publicaram Argentina-Chile. Análisis bistórico, jurídico y político de nuestras relaciones con la república de Chile (1966), demonstrando como o debate sobre territorio e soberanía, quando acionado, é mobilizador.

Apesar de colocados no campo oposto do espectro político de conservadores como Burtillo, eles também trabalharam para resgatar a atuação dos intransigentes e belicistas do século XIX e para denunciar o que chamaram de "uma longa corrente de fatos que o Chile executa para ocupar territórios que são histórica e juridicamente argentinos" (MORENO, 1966, p. 33). A ambos grupos, dos dois lados da cordilheira, era impensável refletir sobre relações com a terra que não passassem pelo modelo estatal ocidental soberanista, excluindo dessa narrativa, por exemplo, as populações indígenas que haviam sido atacadas por ambos Estados.

Em Santiago, Exequiel González Madariaga, ex-senador pelo Partido Radical e apoiador das candidaturas de Salvador Allende e de seu governo da Unidade Popular, publicou Nuestras relaciones con Argentina: una historia deprimente (1970) com uma longa e detalhada história de todas as negociações diplomáticas entre 1856 e 1881 e uma análise coincidente com a dos conservadores, neste assunto, a de que sucessivos governos argentinos postergaram e enganaram os chilenos para se apropriar da 
Patagônia. Para ele, sobre as negociações derradeiras já durante a Guerra do Pacífico: "um projeto sob qualquer aspecto sem vergonha, especialmente quando é considerado que apenas seis meses antes havia sido assinado em Santiago o pacto de arbitragem perseguido pelo próprio governo argentino (p. 251)

Os casos do livro dos peronistas e este de González Madariaga são interessantes, pois demonstram como o debate sobre linhas de fronteiras, tão caro à História das Relações Internacionais, pode sair das chancelarias e ser levado ao grande público. A ponte para a ampliação dos atores e mobilização foi o trabalho desses intelectuais, autores de uma série de livros de título semelhante. Eles pretenderam difundir um debate sobre tema tão caro ao Estado ocidental: a soberania e o controle do território, acionando discursos nacionalistas.

A posse de Salvador Allende na presidência do Chile, em 1970, aumentou ainda mais a gana dos nacionalistas de direita e dos militares argentinos, especialmente após a assinatura da "Declaração de Salta" entre o general presidente Alejandro Lanusse e seu colega chileno, em 1971, indicando a arbitragem britânica para o caso do canal Beagle.

Mais uma vez, os intelectuais tiveram participação ativa no debate público argentino, contribuindo para a "construção de uma crise" (PASSETTI, 2018) que elevaria a tensão política e militar aos mais altos índices até praticamente a declaração de guerra entre ambos países, em 1978.

A conservadora Academia Nacional de História argentina teve atuação direta neste processo, com seus mais destacados integrantes atuando diretamente junto aos militares para pressionar pela denúncia do 
tratado, em 1972, e depois para não aceitar o resultado da arbitragem britânica solicitada pela "Declaração de Salta" (LACOSTE, 2003). Entre os acadêmicos de maior proeminência e atuação naqueles anos, esteve Roberto Etchepareborda, autor do Historia de las relaciones internacionales argentinas (1978).

Neste livro, ele concordou com a leitura hegemônica sobre uma postura agressiva e expansionista do país vizinho. Para ele, por exemplo: “em 1876, um novo ataque de hipertrofia faz com que o país transandino se declare na mais tranquila posse do Estreito e da Patagônia, até a linha do rio Negro" (ETCHEPAREBORDA, 1978, p. 159). Sua análise, no entanto, não se restringiu a este recorte.

Para ele, era preciso reconhecer que a política adotada pela chancelaria argentina resultou positiva a seu país, apesar da constante pressão do país vizinho: "O Chile teve que aceitar um tratado que fixava os limites até o paralelo 52 na cordilheira dos Andes e recebeu a posse do Estreito, mas neutralizado para a perpetuidade. A Patagônia passava assim, definitivamente, a ser incorporada à República” (idem, p. 161). Para aquele historiador, em uma leitura de soma zero, a Argentina venceu a contenda. Isso era importante naquele momento em que a crise por conta do canal Beagle alcançava seu ápice.

O laudo britânico de maio de 1977 indicava a soberania chilena sobre as ilhas.

A ditadura argentina silenciou até janeiro do ano seguinte, quando não reconheceu o resultado. Tal ação, radical no âmbito das relações internacionais, ocorreu amparada pelo silenciamento das oposições pela ditadura, pelo mobilização através da imprensa e pela 
construção destes discursos historiográficos amplamente difundidos à época (PASSETTI, 2018).

Ernesto Fitte, um dos mais ativos articuladores da aproximação entre a Academia Nacional de História e os militares foi um destes efusivos construtores de narrativas na década de 1970, com especial contribuição publicada no exato momento do auge da crise. Em seu Los limites con Chile (1978), ele foi categórico: "Nossa República não conseguiu romper com o fatalismo histórico que a rodeia: cada vez em que precisou resolver questões de limites com seus vizinhos, o acordo foi alcançado invariavelmente à custa de desmembramentos de território argentino" (FIT'TE, 1978, p. 8).

Ao fim, a guerra não foi declarada no último instante. $O$ fim da tensão diplomática e militar não levou ao desaparecimento dessas teses sobre o "expansionismo chileno", sendo ainda vista em obras com menor impacto do que as estudadas até o momento, mas sintomáticas de um discurso arraigado. As obras de diplomatas e historiadores para o grande público perderam espaço, mas havia sido criado outro, na academia conservadora.

O jornalista George V. Rauch publicou, em 1999 em livro sua tese de uma década antes. Conflict in the Southern Cone: the Argentine military and the boundary dispute with Chile, 1870-1902 foi um esforço para levar ao público estadunidense este tema, mas está marcado por uma leitura do autor sobre o Chile, segundo ele "um país menor e naturalmente invejoso" (RAUCH, 1999, p. 173). Para ele, o centro do problema sempre foi o constante expansionismo daquele país: "enquanto a busca 
por soluções continuava, o Chile tratou de ocupar as costas atlânticas da Patagônia” (idem, p. 27).

Leitura semelhante aparece no livro do professor e oficial da reserva da Marinha Argentina, Jorge Bergallo. Em seu 1874-1892. La integración de la Patagonia y el mantenimiento de la paz con Chile, ele repete a tese sobre o expansionismo chileno. Para ele, “será justamente o Chile, com suas atitudes expansionistas, quem colocará em evidência o conflito e alertará a Argentina sobre a necessidade de contar com um poder naval [...] para manter a Patagônia como um espaço sob a jurisdição de suas leis" (BERGALLO, 2020, p. 50). Este autor ainda é o aparentemente único defensor de uma tese sobre a maior relevância da Marinha instituição à qual ele se vinculava - diante do Exército no processo de ocupação territorial. Para ele: "essa Marinha e esses homens colocaram em prática as políticas de um governo e obtiveram para seu país muito mais do que imaginavam. A superfície territorial da região patagônica [...] é argentina graças a eles” (BERGALLO, 2012, p. 20).

Por fim, é preciso também destacar que de igual forma, no Chile também continuaram existindo, de forma igualmente periférica, estudos sobre a cuestión límites pautados pela tese do oportunismo argentino durante a Guerra do Pacífico, como aqueles publicados pelo já encerrado Instituto de Investigaciones del Patrimonio Territorial de Chile (GONZÁLEZ ABUTER, 1988; FERRER FOUGA, 1990).

Após as ditaduras, a nova historiografia e a construção da integração 
A crise internacional com o quase conflito pelas ilhas do Canal Beagle (1978) e depois a Guerra das Malvinas (1982), construída, instigada e defendida pelos mesmos grupos, levaram ao profundo questionamento social a aquelas pessoas. No campo político, a ditadura foi derrubada. No campo intelectual, aquelas ideias foram combatidas e o gradual retorno da vida acadêmica livre incentivou o surgimento de interpretações distintas daquelas belicistas, seja entre historiadores, seja na nascente academia de Relações Internacionais.

O sugestivo título do livro Ganar la paz: encuentro universitário argentino-chileno, de 1984, publicado pela editora da Universidade de Belgrano (Argentina) indica o esforço de uma série de intelectuais para a construção de uma outra história das relações entre aquelas duas sociedades, logo após a Guerra das Malvinas e a queda da ditadura. O tema central que foi se construindo a partir daquele momento, presente na maioria das obras, foi sobre as possibilidades de cooperação, criticando-se intensamente políticos, diplomatas, militares e intelectuais nacionalistas e militaristas dos dois lados dos Andes. Houve o estabelecimento de um novo consenso, crítico aos militares que tomaram o Estado de assalto e também a suas decisões bélicas que levaram os jovens soldados argentinos à morte em defesa de um nacionalismo territorial.

Chama a atenção a publicação deste tipo de livro, contemplando acadêmicos dos dois países, procurando desconstruir explicitamente os discursos belicistas e evidenciar muito mais as semelhanças do que as diferenças entre as duas sociedades. 
Personagem de destaque nessa nova construção intelectual foi Carlos Escudé, cientista político e uma das figuras centrais para a formulação teórica do realismo periférico nas relações internacionais. Em artigo de 1988, ele foi enfático ao criticar os autores das "teses fundacionais" dos dois países: “Quesada e Amunátegui estruturaram seus argumentos como se os desejos da Coroa fossem absolutos e a contradição impensável. Ao procederem assim, ambos incorreram em falácias e ambos mentiram” (ESCUDÉ, 1988, p. 148). Sua análise se centra em como aquele debate da década de 1870 estabeleceu padrões responsáveis por tantos desentendimentos, rivalidades e conflitos posteriores: "Na Argentina há ampla percepção sobre expansão chilena às custas da Argentina [...]. No Chile, há uma percepção paralela sobre expansão argentina às suas custas” (idem, p. 141). Como se vê, há em Escudé uma proposta interpretativa bastante distinta daquela dos autores anteriores e, também, um esforço para criticar e desarmar os discursos nacionalistas em ambos lados da cordilheira.

Escudé também é o organizador, com Andrés Cisneros, da enorme coletânea Historia general de las relaciones exteriores de la República Argentina (2000). Em seu tomo VI, dedicado ao período entre 1860 e 1881, há bastante destaque às relações com o Chile. Além de permanência da análise crítica sobre os criadores das "teses fundacionais", os autores também avançam em muitos temas e apresentam novas questões e debates não elencados pelas gerações anteriores.

É interessante observar como a análise proposta nessa obra procura tirar o foco sobre os "direitos históricos" de cada país. No 
entanto, eles não pretenderam transformar a análise daquele período como algo fácil e naturalmente tendencioso à paz: "enquanto estavam em curso as negociações, os governos muitas vezes dilataram a possibilidade de um acerto, ao mesmo tempo em que procuravam ocupar a zona disputada” (idem, cap. 34).

As tensas negociações diplomáticas não foram simplificadas em algum tipo de versão oposta daquelas leituras nacionalistas e belicistas do processo. Pelo contrário, o que se vê nessa obra e em outras que surgem - por vezes sob princípios teóricos distintos - é a ampliação dos temas, objetos e problemas de pesquisa. Para Escudé e Cisneros, é preciso analisar como as disputas políticas domésticas, o equilíbrio de poder regional, as pressões das potências estrangeiras, os interesses econômicos e os cálculos sobre as possibilidades efetivas bélicas foram importantes para a vitória dos grupos contrários à solução militar. Para eles, acima de tudo, é importante destacar como apesar do imenso ruído promovido pelos discursos nacionalistas e belicistas nos dos países, jamais se recorreu à guerra:

Se bem que as relações diplomáticas entre a Argentina e o Chile tenham conhecido muitos picos de tensão, nunca se chegou a uma guerra aberta pela disputa limítrofe. O governo argentino poderia ter tomado a decisão de se unir a Peru e Bolívia na Guerra do Pacífico contra o Chile, mas ao contrário, se declarou neutro" (CISNEROS, 2000, cap. 34).

Ao longo da década de 1990, o historiador Pablo Lacoste publicou uma série de artigos, concluiu seu doutorado e depois publicou o livro que é a maior referência sobre o tema nessa nova historiografia: La imagen del otro en las relaciones de la Argentina y Chile (1534-2000). Ele voltou aos textos originais, aos arquivos nacionais e europeus para 
rediscutir a construção daquelas que ele cunhou como as "teses fundacionais" do debate sobre fronteiras.

Sua análise de autores como Quesada e Amunátegu, sobre os documentos e mapas históricos se consolidou como a referencial sobre o tema. Ele é enfático ao afirmar que aqueles autores "selecionaram exclusivamente os antecedentes favoráveis aos interesses de seus respectivos países e redigiram ensaios e informes que, à primeira vista podiam parecer contundentes e sólidos” (LACOSTE, 2002, p. 275). No entanto, baseados em distorções, seleções e mentiras "os antigos mapas e suas versões modernas se transformaram em transmissores de um discurso de poder, no qual se mostrava uma identidade nacional distorcida e uma imagem do vizinho carregada de xenofobia" (idem, p. 218).

No entanto, sua análise avança à crítica às manipulações já levantadas por outros historiadores. Ele busca explicitar como as chancelarias - exceto nos momentos em que as negociações estiveram nas mãos de Ibañez e Félix Frías - mantiveram posturas mais conciliadoras do que o ruído promovido pelas "teses fundacionais" poderia parecer. Ao destacar este tipo de postura, Lacoste é mais um historiador do período pós-ditaduras a promover as aproximações, semelhanças e uma história de paz e integração. Para ele:

o tratado de 1881 foi a prova final do escasso apoio da classe dirigente chilena à tese de Amunátegui [...]. Cabe destacar que nenhum desses convênios foi assinado durante a Guerra do Pacífico [...]. A classe dirigente chilena não atuou sob pressão [...]. Pelo contrário, em todo esse tempo suas Forças Armadas eram superiores às da Argentina. Simplesmente se pode dizer que o Chile não concordava com as teses fundacionais de Amunátegui (idem, p. 293). 
Para Lacoste, é preciso diminuir o peso daqueles polemistas do século XIX sobre as chancelarias sem, no entanto, deixar de reconhecer a importância daquelas obras para a construção de imagens muito negativas de cada país para o outro.

Novas pesquisas têm se aprofundado na construção dessas crises, nos interesses políticos e econômicos envolvidos na ocupação dos territórios patagônicos e nos embates eleitorais. O historiador Mauricio Rubilar Luengo, por exemplo, tem pesquisado imprensa e relações internacionais e, especificamente como os jornais de Buenos Aires retrataram a Guerra do Pacífico em conexão com a disputa patagônica. Para ele, houve a "formulação de um discurso jornalístico que definiu à república do Pacífico uma conduta 'agressiva e expansionista' na guerra, com potenciais efeitos negativos para os interesses nacionais argentinos" (RUBILAR LUEGO, 2019, p. 224).

Já para a historiadora econômica Agustina Rayes, “o principal interesse do Chile foi em conservar o Estreito de Magalhães [...] em uma era em que o transporte marítimo dominava, reclamou a Patagônia [...] como estratégia de exigir mais para obter pelo menos o verdadeiramente pretendido" (RAYES, 2010, p. 235). A partir destes novos enfoques, a análise sobre o tema tem se ampliado e complexificado, afastando-se das simplificações construídas no século XIX e repetidas até o período das mais recentes ditaduras.

Os novos temas e aportes metodológicos à análise da cuestión limites fizeram surgir uma profusão de novas pesquisas críticas aos nacionalismos, aos usos e manipulações dos documentos históricos espanhóis e ao militarismo. Eles indicam a preocupação recorrente em 
entender a escalada da crise de 1978 e como aquele tipo de situação pode ser impedido através da adesão a processos de integração e cooperação de corte liberal.

\section{Considerações finais: os intelectuais e a política internacional}

A análise aqui proposta teve como foco as disputas entre os Estados argentino e chileno pelas terras da Patagônia, do Estreito de Magalhães e da Terra do Fogo. O recorte analítico foi a relação entre a produção e o engajamento dos intelectuais dos dois países nos debates e na construção de narrativas e discursos sobre identidades nacionais, soberanias, territórios e o caráter do povo vizinho.

Como pretendemos demonstrar, cada fase de acirramento das relações internacionais entre os dois países foi antecedida por efervescência intelectual e debates públicos que levaram à mobilização nos dois lados da cordilheira. Esses não apenas repercutiram a tensão diplomático-militar, como ajudaram a construí-las e deram sustentação intelectual às argumentações colocadas.

Na década de 1850, na sequência da ocupação chilena de Punta Arenas, intelectuais de Buenos Aires e Santiago deram início à busca por documentos coloniais espanhóis que embasassem a reivindicação de um Estado ou de outro pelo extremo sul do continente. Este debate se ampliou e alcançou seu ápice na década de 1870, com intensos debates intelectuais e diplomáticos e alta tensão internacional. Um século depois, aqueles debates foram redescobertos na construção de nova crise que quase levou a uma guerra por três ilhas no Canal Beagle. 
Após a queda das duas ditaduras, abriu-se espaço intelectual para a revisão daquela antiga história diplomática baseada em oposições, simplificações e construções de rivalidades. Pretendendo superar a experiência da quase guerra de 1978 e baseados em novas pesquisas históricas e no entendimento liberal das relações internacionais de que a integração e a cooperação diminuem desentendimentos, conflitos e inimizades, uma nova leva de produtos intelectuais procurou destacar as aproximações e semelhanças entre aqueles povos. Tema que ainda mobiliza paixões, a rivalidade entre Argentina e Chile tende a ressurgir de tempos em tempos e a atuação dos intelectuais tem sido intensa e sistemática na construção de canhões e de pontes.

\section{Referências}

AMUNÁTEGUI, Miguel Luis. Títulos de la República de Chile a la soberanía i dominio de la estremidad austral del continente americano. Santiago: Imprenta Nacional, 1853.

. La cuestión de límites entre Chile i la República

Arjentina. Santiago: Imprenta Nacional, 3v, 1879-1880.

ARANDA, María Marcela. Francisco A. Encina en la historia de las ideas latino-americanas. Estudios Avanzados, Santiago, n. 11, 2009, pp. 99122.

BARROS ARANA, Diego. La cuestión de límites entre Chile i la República Arjentina. Santiago: Cervantes, 1895.

BARROS VAN BUREN, Mario. Historia diplomática de Chile (15411938). Barcelona: Ariel, 1970. 
BERGALLO, Jorge. 1874-1892. La integración de la Patagonia y el mantenimiento de la paz con Chile. Buenos Aires: Instituto de Publicaciones Navales, 2012.

BORGOÑO, Luis Barros. A través de una correspondencia: Misión en el Plata 1876-1878. La cuestión de límites, Barros Arana diplomático y perito. Santiago: Prensa de la Universidad de Chile, 1936.

BUSTILLO, Exequiel. Problemas de nuestra frontera patagónica. Buenos Aires: Kraft, 1965.

CISNEROS, Andrés; ESCUDÉ, Carlos (org). Historia general de las relaciones exteriores de la República Argentina. Buenos Aires: Grupo editor latinoamericano, 2000.

CRISTI, Renato; RUIZ, Carlos Ruiz. Conservative Thought in Twentieth Century Chile. Canadian Journal of Latin American and Caribbean Studies, v. 15, n. 30, 1990.

DE ANGELIS, Pedro. Colección de obras impresas y manuscritas que tratan principalmente del Río de la Plata. Buenos Aires: 1852.

ENCINA, Francisco Antonio. La cuestión de límites entre Chile y la Argentina desde la independencia hasta el tratado de 1881. Santiago: Nascimento, 1959.

ESCUDÉ, Carlos. Argentine territorial nationalism. Journal of Latin American Studies, vol. 20, n. 1, 1988, pp. 139-165.

ETCHEPAREBORDA, Roberto. Historia de las Relaciones Internacionales Argentinas. Buenos Aires: Pleamar, 1978.

FERRER FOUGA, Hernán. Proceso de conformación territorial de Chile (1536-1881). Santiago: Instituto de Investigaciones del Patrimonio Territorial de Chile, 1990.

FITTE, Ernesto. Los límites con Chile. Buenos Aires: Plus Ultra, 1978.

FRÍAS, Félix. Cuestión chileno-argentina: notas diplomáticas y otros escritos en defensa de los derechos de la República Argentina. Buenos Aires: Imprenta y Librería de Mayo, 1877. 
GONZÁLEZ ABUTER, Tulio. Negociaciones chileno-argentinas de límites (1871-1881). Santiago: Instituto de Investigaciones del Patrimonio Territorial de Chile, 1988.

GREJO, Camila Bueno. A construção da identidade internacional argentina por Estanislao Zeballos nas páginas da Revista de Derecho, Historia y Letras. Antíteses, v. 10, n. 19, 2017, pp. 64-87.

HARAMBOUR, Alberto. Soberanías fronterizas. Estados y capital en la colonización de la Patagonia (Argentina y Chile, 1830-1922). Valdivia: Ediciones UACh, 2019.

HEINSFELD, Adelar. Argentina x Chile: fronteira e corrida armamentista no Cone Sul no final do século XIX. História: debates e tendências, v. 19, n. 3, 2019, pp. 531-548.

IMAZ, José Luis de; LAGOS, Gustavo (et al). Ganar la paz: encuentro universitario argentino-chileno. Buenos Aires: Belgrano, 1984.

LACOSTE, Pablo. La Academia Nacional de Historia y el conflicto del Beagle (1960-1984). Historiografía, Puerto Madryn, v. 1, 2003, pp. $195-$ 224.

LACOSTE, Pablo. La imagen del otro en las relaciones de la Argentina y Chile (1534-2000). Santiago/Buenos Aires: Universidad de Chile/FCE, 2003.

MORENO QUINTANO, Lucio; SERRANO, Mario; STEFFENS SOLER, Carlos; LLAMBÍ, Benito P.; TASCHERET, Oscar; VAILATI, Guillermo J. Argentina-Chile. Análisis histórico, jurídico y político de nuestras relaciones con la república de Chile. Buenos Aires: CISA, 1966.

MORLA VICUÑA, Carlos. La cuestión límites entre Chile y la República Argentina. Valparaiso: Imprenta de la Patria, 1979.

MOTTA, Manuel Antonio. La cuestión chileno-arjentina. Santiago: Imprenta de la librería del Mercurio, 1874.

MYERS, Jorge. Músicas distantes. Algumas notas sobre a história intelectual hoje: horizontes velhos e novos, perspectivas que se abrem. 
In: SÁ, Maria Elisa Noronha de (org). História intelectual latinoamericana. Rio de Janeiro: Editora da PUC-Rio, 2016.

NEIBURG, Federico. Os intelectuais e a invenção do peronismo. São Paulo: Edusp, 1997.

PACHECO, Vanessa Moraes. Miguel Luís Amunátegui e o debate histórico no Chile do século XIX. Mestrado em História Social, USP, São Paulo, Brasil, 2012.

PASSETTI, Gabriel. A construção de uma crise: usos da história por intelectuais argentinos na contestação aos tratados com o Chile nas décadas de 1960 e 1970. Diálogos, v. 22, n. 1, 2018, pp. 139-156.

. O mundo interligado: poder, guerra e território nas lutas na Argentina e na Nova Zelândia (1826-1885). Tese em História Social, USP, São Paulo, Brasil, 2010.

PODGORNY, Irina. Fronteras de papel: archivos, colecciones y la cuestión de límites en las naciones americanas. Historia Crítica, Bogotá, n. 44, 2011, pp. 56-79.

PRADO, Maria Ligia Coelho. Repensando a história comparada da América Latina. Revista de História, São Paulo, n. 153, 2005, pp. 1133.

QUESADA, Vicente. La Patagonia y las tierras australes del continente americano. Buenos Aires : Imprenta y Librerías de Mayo, 1875.

RAUCH, George V. Conflict in the Southern Cone: the Argentine military and the boundary dispute with Chile, 1870-1902. Santa Barbara: Praeger, 1999.

RAYES, Agustina. La relación bilateral gubernamental entre la Argentina y Chile, 1862-1880. La dimensión del conflicto. Temas de Historia Argentina y Americana, v. XVII, 2010, pp. 199-236.

RUBILAR LUENGO, Mauricio; RETAMAL FERRADA, Lorena. La Prusia de América: imagen internacional de Chile en la prensa de Buenos Aires durante la Guerra del Pacífico (1879-1881). In: RUBILAR 
LUENGO, Mauricio; SÁNCHEZ ANDRÉS, Agustín (coord.) Relaciones internacionales y construcción nacional. América Latina 1810-1910. Concepción: Universidad Católica de la Santísima Concepción; Morelia: Universidad Michoacana de San Nicolás de Hidalgo, 2019.

SANTOS, Eduardo dos. Entre o Beagle a as Malvinas: conflito e diplomacia na América do Sul. Brasília: FUNAG, 2016.

SANTOS, Luis Claudio Villafañe Gomes. O Império e as Repúblicas do Pacífico. As relações do Brasil com Chile, Bolívia, Peru, Equador e Colômbia. Curitiba: EdUFPR, 2002.

SCHEIDT, Eduardo. Carbonários no Rio da Prata: jornalistas italianos e a circulação de idéias na Região Platina (1827-1860). Rio de Janeiro: Apicuri, 2008.

TELLES, Manuel Ricardo. Cuestión de límites entre la República Argentina y el gobierno de la República de Chile. Buenos Aires: Imprenta de la Sociedad Tipográfica Bonaerense, 1865.

TORO HURTADO, Gaspar. La diplomacia chileno-arjentina: cuestión de límites. Santiago: Imprenta del Mercurio, 1878.

VÉLEZ SARSFIELD, Dalmacio. Discusión de los títulos del gobierno de Chile a las tierras del Estrecho de Magallanes. Buenos Aires: Imprenta Argentina, 1853.

VILLAR G., Andrés. Autonomy and negotiation in foreign policy. The Beagle Channel crisis. Londres: Palgrave Macmillan, 2016. 